\title{
Inhibitory and Anti-Biofilm Effects of Orthoshipon aristatus Against Candida albicans
}

\author{
Ratika Rahmasari $^{1}$, Ananda Hanny Chairunissa ${ }^{1}$, Marina Ika Irianti ${ }^{1}$, Roshamur Cahyan \\ Forestrania $^{1}$, Ayun Arifianti' ${ }^{1}$ Herman Suryadi', Juliann Nzembi Makau ${ }^{2}$, Ibrahim Jantan ${ }^{3}$, \\ Berna Elya $^{1 *}$ \\ ${ }^{1}$ Faculty of Pharmacy, Universitas Indonesia, Depok, West Java. Indonesia \\ ${ }^{2}$ Nagasaki University, Japan \\ ${ }^{3}$ The Institute of Systems Biology (INBIOSIS), Universiti Kebangsaan Malaysia, Selangor, Malaysia
}

\begin{abstract}
There are increasing number of reports on Candida albicans developing resistance to available antifungal drugs. Thus, there is an urgent need to discover new agents for treatment of candidiasis. The alcoholic extracts of Orthoshipon aristatus have been shown to exhibit antifungal activity against C. albicans by using the agar diffusion and broth microdilution methods. However, the underlying mechanisms of anti-C. albicans effect of $O$. aristatus have not been well understood. This study was aimed to evaluate the cytotoxic and anti-biofilm effects of the n-hexane and ethanol extracts of purple and white varieties of $O$. aristatus leaves and branches against $C$. albicans. The effect of n-hexane and ethanol extract against $C$. albicans growth was carried out by crystal violet viability assay. $\mathrm{IC}_{50}$ values of the most active extract, and nystatin and fluconazole as positive controls were also determined by the crystal violet assay. Evaluation of the anti-biofilm effect was performed by treating $C$. albicans with the extracts at adhesion, development, and biofilm maturation stages using 3-(4,5-dimethylthiazol-2-yl)-2,5-diphenyltetrazolium bromide (MTT) assay. The n-hexane extract of the purple variety of $O$. aristatus leaves demonstrated the strongest cytotoxic activity against $C$. albicans amongst the tested extracts, with an $\mathrm{IC}_{50}$ value of $0.67 \mu \mathrm{g} / \mathrm{mL}$. The extract also showed strong anti-biofilm effect as fluconazole, with pronounced inhibition at the adhesion stage and less activity at the biofilm development and maturation stages. These results suggested that the n-hexane extract of the purple variety of $O$. aristatus leaves could be explored for discovery and development of anti-C. albicans agent.
\end{abstract}

Keywords: Orthoshipon aristatus; anti-Candida albicans; cytotoxic; anti-biofilm

*corresponding author

Email:berna.elya@farmasi.ui.ac.id

\section{INTRODUCTION}

Candida albicans is an oval and unicellular commensal microorganism found in the skin, vaginal and respiratory mucosa. However, it can turn into a pathogen and cause superficial and systemic candidiasis mainly caused by immune suppression (Kadosh \& Lopez, 2013). Candidias can usually be suppressed by fluconazole, however in recent years it has been reported that the incidence of C. albicans resistance against azole and nystatin has been increasing (Oxman et al., 2010; Mohamadi et al., 2014; Sandai et al., 2016). The presence of biofilms and wide use of azole drugs have been identified as one of the resistance factor (Lortholary et al., 2010). Thus, the emergence of $C$. albicans resistance is the major driving factor for development of novel anti-Candida albicans drugs.

Numerous reports showed that natural products such as herbal medicine or its derivatives possess potential antiviral, antimicrobial, or anti-fungal activity (Atanasov et al., 2015). Manuka honey has been reported not only to exhibit antibacterial activity but also antiviral activity (Watanabe et al., 2014). Epigallocatechin gallate was also demonstrated to exhibit the Zika virus growth in vitro (Raekiansyah et al., 2018). Furthermore, Rooibos tea showed activity against Influenza virus type A and B (Rahmasari et al., 2017). Consequently, the anti-fungal activities of herbal medicines, and their constituents are of great research interest.

Orthosiphon aristatus is a plant distributed across South East Asia and South Asia. It is also known as kumis kucing in Indonesia, misai kucing in Malaysia, and java tea in United States. It is traditionally used for the treatment of kidney stone bladder, vaginitis, urinary infection, and rheumatoid (Mukesh et al., 2015). There are two varieties of $O$. aristatus grown in Indonesia, namely, white and purple flower. To note, the purple variety is known to contain more bioactive compounds compared to the white variety (Ashraf et al., 2015). In general, $O$. aristatus has been reported to contain the 
glycoside orthoshipon, terpenoids, and flavonoids such as eupatorin, sinensetin, salvigenin, ladanein, vomifoliol, 5-hydroxy-6,7,3', $4^{\prime}$ - tetramethoxyflavone, 6-hydroxy5,7,4'-trimethoxyflavone, 7,3',4'-tri-O-methylluteolin, tetramethylscutellarein and scutellarein tetramethylether (Lyckender \& Malterud, 1996; Tezuka et al., 2000). A previous study used the agar diffusion method to demonstrate the anti-C. albicans activity of ethanol extract of $O$. aristatus (Romula et al., 2018). However, the effect of direct contact between various extracts of $O$. aristatus and C. albicans cells as well as the analysis of the possible mode of action, have not been reported. In the present study, we investigated the anti-C. albicans activity of n-hexane and ethanol extracts of both white and purple varieties of $O$. aristatus by evaluating their cytotoxic and anti-biofilms effects. We found that the n-hexane extract of leaves of the purple $O$. aristatus potently suppressed the viability of $C$. albicans and interfered with the adhesion stage in biofilm formation.

\section{MATERIALS AND METHODS}

\section{Cells and Samples \\ Candida albicans ATCC 10231 were grown in a 90 mm-} petri dish containing potato dextrose agar (Wako Pure Chemical Industries, Osaka, Japan) and maintained in an incubator at $28^{\circ} \mathrm{C}$. For experimental purposes, $C$. albicans from the petri dish were further transferred into slant potato dextrose agar and incubated at $28^{\circ} \mathrm{C}$ for 24 h. Nystatin (Metiska Farma, Jakarta, Indonesia) and fluconazole (Novell Pharmaceutical Laboratories, Jakarta, Indonesia) were dissolved in ultrapure water. Dried of 3 months old $O$. aristatus white and purple varieties were purchased from Balai Penelitian Obat dan Rempah Indonesia on August, 2019 (Bogor, Indonesia) and identified in Lembaga Ilmu Pengetahuan Indonesia (Indonesian Institute of Science, Bogor Indonesia).

\section{Extract Preparation}

One gram each of dried branches and leaves of white and purple varieties of $O$. aristatus was extracted with 100 $\mathrm{mL}$ of $\mathrm{n}$-hexane (Wako Pure Chemical Industries, Osaka, Japan) and shaken at $37^{\circ} \mathrm{C}$ for $3 \mathrm{~h}$. After Whatman paper filtration, the filtrate was vacuum evaporated to obtain the n-hexane extract and the residue was further extracted by $96 \%$ ethanol (Wako Pure Chemical Industries, Osaka, Japan) and shaken at $37^{\circ} \mathrm{C}$ for $3 \mathrm{~h}$. After centrifugation at $3000 \mathrm{rpm}$ for $15 \mathrm{~min}$ (Tomy Mx-305), the extract was filtrated by Whatman paper and vacuum evaporated to obtain the ethanol extract. The dried extracts were dissolved in DMSO $(0.2 \mathrm{~g} / \mathrm{mL})$ and the final DMSO concentration in each reaction mixture was $1 \%$.

\section{Crystal Violet Viability Assay}

The crystal violet viability assay was carried out using a 96 well-culture plate coated with $50 \%$ fetal bovine serum
(Sigma Aldrich, St. Louis, America). A volume of 100 $\mu \mathrm{L} /$ well of tested extract diluted in sabouraud dextrose broth (SDB) (Wako Pure Chemical Industries, Osaka, Japan) was added into 96 well-culture plates followed by the addition of $100 \mu \mathrm{L} /$ well of $C$. albicans $\left(3 \times 10^{4}\right.$ cells/well) in SDB. The mixture was then incubated at $28^{\circ} \mathrm{C}$ for $48 \mathrm{~h}$. The supernatant was then aspirated, and the cells were fixed with $70 \%$ ethanol and stained with $0.5 \%$ crystal violet. Cells were dried and diluted by $96 \%$ ethanol. The absorbance was measured at $460 \mathrm{~nm}$ using a microplate reader (VersaMax Molecular Devices, California, USA).

The selected extract of $O$. aristatus which shown highest activity in inhibiting $C$. albicans were subjected to a serial dilution to obtain solutions of $2,1,0.5,0.25$, $0.125,0.062,0.031$ and $0.016 \mathrm{mg} / \mathrm{mL}$. The percentage inhibition was calculated using Microsoft Excel software, and the 50\% inhibition concentration $\left(\mathrm{IC}_{50}\right)$ was determined by linear regression analysis.

\section{Biofilm Susceptibility Assay}

MTT(3-(4,5-dimethylthiazol-2-yl)-2,5-diphenyltetrazolium bromide) assay was carried out to evaluate the efficacy of $O$. aristatus extracts in interrupting biofilm formation using 96 well-flat bottom polystyrene titre plates according to Traba and Liang (2011). Evaluation of the inhibitory effects was performed by treating C. albicans at adhesion, development, and biofilm maturation stages using a modified time of addition assay by Raut et al. (2013). In brief, $100 \mu \mathrm{L} /$ well of $C$. albicans $\left(3 \times 10^{6}\right.$ cells/well) in SDB was dispensed aseptically into 96 well-culture plates coated with $50 \%$ fetal bovine serum (Sigma Aldrich). For the adhesion stage study, the plate was incubated at $37^{\circ} \mathrm{C}$ for $2 \mathrm{~h}$ with and without extract. Supernatant then was aspirated, followed by the addition of $100 \mu \mathrm{L} /$ well of fresh SDB and $50 \mu \mathrm{l} /$ well MTT in $0.15 \mathrm{M}$ PBS (1:5). After $3 \mathrm{~h}$ of incubation under dark condition at room temperature, $50 \mu \mathrm{L} /$ well of DMSO was added. The absorbance was then measured at 570 $\mathrm{nm}$ (Versa Max). For the biofilm development stage, after $2 \mathrm{~h}$ of incubation at $37^{\circ} \mathrm{C}$, the supernatant was aspirated and washed by PBS to remove non adhered cells followed by the addition of fresh SDB (100 $\mu \mathrm{l} /$ well) with and without extract and incubation at $37{ }^{\circ} \mathrm{C}$ for $24 \mathrm{~h}$. The cell viability was measured by MTT reagent (Sigma Aldrich, St. Louis, America). MTT assay was carried out by monitoring the reduction of MTT after $3 \mathrm{~h}$ of incubation under dark conditions. The reduction product was solubilized in DMSO (50 $\mu \mathrm{l} /$ well), and OD was read at $570 \mathrm{~nm}$. The biofilm maturation stage study was carried out by using $24 \mathrm{~h}$ old biofilm. Wells with 24 $\mathrm{h}$ old biofilm were washed with PBS followed by the addition of $100 \mu \mathrm{l} /$ well SDB (with or without extract). Cells were further incubated at $37^{\circ} \mathrm{C}$ for $48 \mathrm{~h}$, and cell viability was then measured by MTT as described above. 


\section{Statistical Analysis}

The data were presented as means \pm standard error (SE) from three independent experiments. Each test condition was carried out in triplicate. The $\mathrm{IC}_{50}$ values of the samples were obtained from at least three determinations. In order to avoid the artefact activity, negative control (medium containing solvent or medium containing extract without $C$. albicans) were also tested.

\section{RESULTS}

Figure 1 shows that the n-hexane and ethanol extracts of white $(\mathrm{W})$ and purple $(\mathrm{P})$ varieties of $O$. aristatus leaves (WL, PL) and branches (WB, PB) could inhibit C. albicans viability as indicated by lower $\%$ relative C. albicans cell density as compared to the negative control. Treatment with $3.125 \mathrm{UI} / \mathrm{mL}$ nystatin (equal to $0.62 \mu \mathrm{g} / \mathrm{ml}$ ) as a positive control, resulted in the lowest C. albicans cell viability. The ethanol extracts of both white and purple varieties (WL, WB, PL, PB) exhibited strong cytotoxicity with $50 \%$ relative cell density while the n-hexane extracts of $\mathrm{WL}, \mathrm{WB}$ and $\mathrm{PB}$ of $O$. aristatus showed relatively higher \% cell viability. Among the extracts tested, the n-hexane extract of PL variety showed the lowest \% relative $C$. albicans cell density. The n-hexane extract of $O$. aristatus PL was also observed as the only extract which caused less than $50 \%$ of relative $C$. albicans cell density as compared to the negative control. The $\mathrm{IC}_{50}$ value of the $\mathrm{n}$-hexane extract of $O$. aristatus PL was $1.3 \pm 0.15 \mathrm{mg} / \mathrm{mL} \mathrm{mg} / \mathrm{mL}$ which was higher than that of nystatin $(0.07 \pm 0.002 \mu \mathrm{g} /$ $\mathrm{mL})$ and fluconazole $(3.36 \pm 0.7 \mu \mathrm{g} / \mathrm{mL})$ as shown in Table 1 respectively.

Table 1. $\mathrm{IC}_{50}$ value

\begin{tabular}{ll}
\hline Sample & IC $_{\mathbf{5 0}}$ Value $(\mu \mathrm{g} / \mathrm{mL})$ \\
\hline n-hexane extract PL & $1300 \pm 150$ \\
Nystatin & $0.07 \pm 0.002$ \\
Fluconazole & $3.36 \pm 0.7$ \\
\hline
\end{tabular}

PL, leaves of purple variant

In the biofilm inhibition assay, fluconazole, a widely used anti-fungal drug was used as the positive control (Maubon et al, 2014). The addition of n-hexane extract of $O$. aristatus PL and fluconazole at the adhesion stage showed a significant decrease of C. albicans cells compared to untreated cells (Figure 2). The n-hexane extract of $O$. aristatus PL reduced $C$. albicans viability by more than $10 \%$ than that of fluconazole at the adhesion stage. The n-hexane extract of $O$. aristatus PL caused $69.2 \%$ decrease of $C$. albicans cells, higher than that of fluconazole $(54.7 \%)$. At the development stage, mild inhibition activity of $C$. albicans growth was observed for both n-hexane extract of $O$. aristatus PL (57.1\%) and fluconazole (57.3\%). However, both n-hexane extract and fluconazole caused less inhibition to a mature biofilm.

\section{DISCUSSION}

The anti-C. albicans activity of $O$. aristatus purple and white varieties extracts were evaluated using the crystal violet $(\mathrm{CV})$ viability assay. $\mathrm{CV}$ stained the adherent live $C$. albicans cells. Meanwhile, the dead cells of $C$. albicans, following sample treatment, were detached from the culture dish. Low activity of sample against C. albicans cells prevented cells from detachment, leading to high levels of CV staining similar to untreated cells (negative control). In this assay nystatin was used as a positive control because of its susceptibility against $C$. albicans (Khan et al., 2018). Screening and $\mathrm{IC}_{50}$ evaluation of the ethanol dan n-hexane extracts of purple dan white variants of $O$. aristatus branches and leaves indicated that the n-hexane extract of $O$. aristatus PL showed the strongest cytotoxic effect on $C$. abicans This result suggested that the extract could be a potential source for discovery of lead compound for development of antifungal agent against $C$. albicans infection.

One of the virulence factors of $C$. albicans is the ability to form a biofilm (Lohte et al., 2018). Thus, the effect of n-hexane extract of $O$. aristatus PL against biofilm formation was evaluated at adhesion, development, and maturation stage of biofilm formation. In the biofilm formation assay, fluconazole was used as the positive control to inhibit the adhesion process of $C$. albicans. The n-hexane extract of $O$. aristatus PL showed a similar inhibitory result as fluconazole with pronounced inhibition at the adhesion stage and less activity at the biofilm development and maturation stages, respectively. Fluconazole was reported not only disrupted the membrane and wall integrity but also decreased the incorporation of hyphal-associated wall proteins (As3, hwp1, and P1b5) and wall repaired related protein, which interferes the C. albicans adhesion process (Sorgo et al., 2011). In the adhesion process, cell wall proteins such as hwp1 play indirect roles in the adhesion process (McCall et al., 2011).

Neharkar \& Laware (2013) reported the antifungal activity of hydro-alcoholic extract of $O$. stamineus against $C$. albicans by using the disk and agar diffusion method. The anti-C. albicans activity of the plant was further confirmed by Romulo et al. (2018) who screened the antifungal activity of the ethanol extracts of many Indonesian plants including $O$. aristatus using the broth microdilution method. However, they didn't mention the varieties of tested Orthosiphon aristatus. Among the 


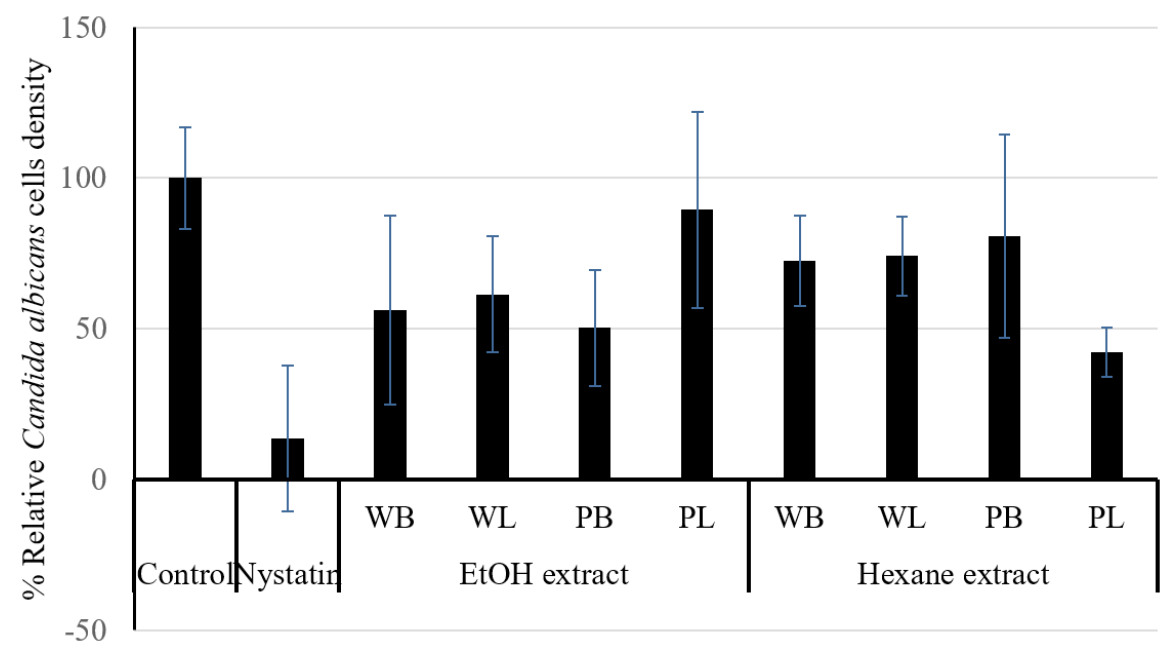

Figure 1. The cytotoxic effect of $O$. aristatus extracts $(100 \mu \mathrm{L} /$ well $)$ against C. albicans. Data are represented as the mean \pm standard error - from two independent experiments (each in triplicate). Nystatin was tested at $500 \mathrm{UI} /$ mL. Control, untreated cells; WB, branch of white variant; WL, leaves of white variant; PB, branch of purple variant; PL, leaves of purple variant.

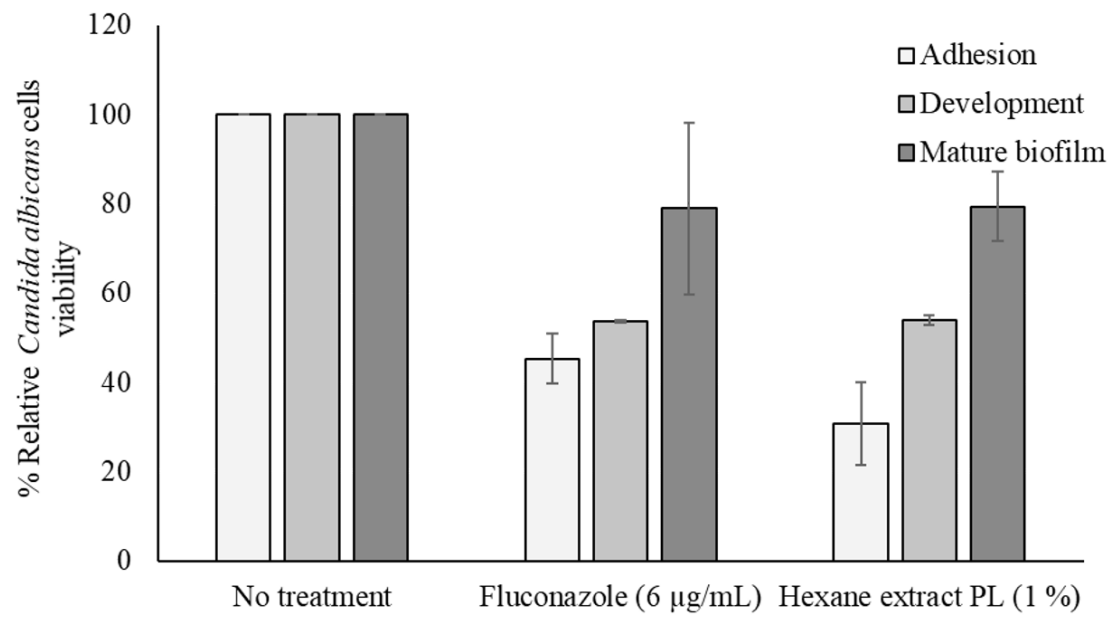

Figure 2. Inhibition of biofilm development of $C$. albicans by the n-hexane extract of leaves of $O$. aristatus purple variant (PL) $(2 \mathrm{mg} / \mathrm{mL})$ and fluconazole $(6 \mu \mathrm{g} / \mathrm{mL})$. Data are represented as the mean \pm standard error of mean from two independent experiments (each in triplicate).

plants investigated, the extract of $O$. aristatus exhibited the strongest antimicrobial effect, inhibiting the growth of $C$. albicans at MIC value of $128 \mu \mathrm{g} / \mathrm{mL}$. The active components of $O$. aristatus extract in these studies were polar and possibly phenolic. The anti-fungal action of phenolic compounds have been suggested to be through cell membrane disruption, inhibition of cell wall formation, and inhibition of the mitochondria (Freiesleben \& Jager, 2014; Shahzad et al., 2014). In this study, we demonstrated for the first time that the n-hexane and ethanol extracts of white and purple varieties of $O$. aristatus, exhibited inhibitory activity against $C$. albicans due to their cytotoxic and anti-biofilm effects. The results revealed that the n-hexane extract of $O$. aristatus PL possessed the strongest activity against
C. albicans compared to the other tested extracts. The extract mainly inhibited the adhesion stage of biofilm formation.

The active constituents of the n-hexane extract of $O$. aristatus PL, which were responsible for inhibiting C. albicans, have not been identified. The n-hexane extract contained non polar constituents of $O$. aristatus including the essential oils. Hossain et al. (2008) identified the chemical composition and anti-fungal effects of the essential oil of $O$. stamineus against various phytopathogenic fungi. The oil was mainly consisted of terpenoids with $\beta$-caryophyllene, $\alpha$-humulene, $\beta$-elemene, $\beta$-bourbonene and caryophyllene oxide as the major sesquiterpenes while 1-octen-3-ol, $\beta$-pinene, 
camphene and limonene were the major monoterpenes. Terpenoids have been reported to be able to disrupt the cell membrane, and some of them were also able to destroy the fungal mitochondria (Freiesleben \& Jager, 2014). In addition, it was reported that terpenoids potentially inhibited $C$. albicans cells growth at the hyphal form, which is also important for adhesion maintaining process of biofilm formation (McCall et al., 2019; Zore et al, 2011). Thus, it is proposed that active compound(s) of n-hexane extract of $O$. aristatus PL might block the adhesion process by disrupting the hyphal form. However, further evaluation is needed to understand the underlying mechanism.

\section{CONCLUSION}

Our present results suggest that the n-hexane extract of leaves of a purple variant of $O$. aristatus has potent inhibitory effects against $C$. albicans. Further studies are necessary to identify the bioactive constituents contributing to the antifungal activity and an indepth study to understand the underlying mechanisms of anti-C. albicans effect. The toxicity of the plant extract against human cell line should also be carried out to determine its safety for human use.

\section{REFERENCES}

Atanasov, A.G., Waltenberger, B., Pferschy-Wenzig, E.M., Linder, T., Wawrosh, C., Uhrin, P., et al. (2015). Discovery and resupply of pharmacologically active plant-derived natural products: A review. Biotechnology Advances, 33:1582-1161.

Ashraf, K., Sultan S, Adam A. Orthoshipon stamineus Benth, is an outstanding food medicine: Review of phytochemical and pharmacological activities. Journal of Pharmacy and Bioallied Sciences, 10:109-118.

Freiesleben, S.H,, Jager, A.K. (2014). Correlation between plant secondary metabolites and their antifungal mechanisms-A review. Medicinal \& Aromatic Plants, 3:154-160.

Hossain, M.A., Ismail, Z., Rahman, A., Kang, S.C. (2008). Chemical composition and anti-fungal properties of the essential oils and crude extracts of Orthosiphon stamineus Benth. Industrial Crops and Products, 27:328-334.

Kadosh D., Lopez-Ribot, J.L. (2013). Candida albicans: Adapting to succeed. Cell Host \& Microbe, 14:483-485

Khan, M., Ahmed, J., Gul, A., Ikram, A., Lalani, F.K. (2018). Anti-fungal susceptibility testing of vulvovaginal Candida species among women attending antenatal clinic in tertiary care hospitals of Peshawar. Infection and Drug Resistance, 11:447-456.

Lohse, M., Gulati, M., et al. Development and regulation of single- and multi-species Candida albicans biofilms. Nature Reviews Microbiology,16:19-31.

Lortholary, O., Desnos-Ollivier, M., Sitbon, K., Fontanet, A., Bretagne, S., Dromer, F. (2011). Recent exposure to caspofungin or fluconazole influences the epidemiology of candidemia: a prospective multicenter study involving 2,441 patients. Antimicrobial Agents and Chemotherapy, 55:532-538.

Lyckender, I.M., Malterud, K.E. (1996). Lipophillic flavonoids from Orthosiphon spicatus prevent oxidative inactivation of 15-lipoxygenase. Prostaglandins, Leukotrienes \& Essential Fatty Acids, 54:239-246.

Maubon, D., Garnaud, C., Calandra, T., Sanglard, D., Cornet, M. (2014). Resistance of Candida spp. to antifungal drugs in the ICU: where are we now? Intensive Care Medicine, 40 (9): 1241-1255.

McCall, A.D., Pathirana, R.U., Prabhakar, A., Cullen, P.J., Edgerton, M. (2019). Candida albicans biofilm development is governed by cooperative attachment and adhesion maintenance proteins. Biofilms and Microbiomes, 5: 21.

Mohamadi, J., Motaghi, M., Panahi, J., Havasian, M.R., Delpisheh, A., Azizian, M., et al. (2014). Anti-fungal resistance in candida isolated from oral and diaper rash candidiasis in neonates. Bioinformation, 10:667-670.

Mukesh, K.Singh., Bina, Gidwani., Anshita, Gupta., Hemant, Dhongade., Chanchal Deep Kaur., Pranita, P. Kashyap., D.K. Tripathi. (2015). A Review of the medicinal plants of genus orthosiphon (Lamiaceae). International Journal of Biological Chemistry, 9:318331.

Oxman, D.A., Chow, J.K., Frendl, G., Hadley, S., Hershkovitz, S., Ireland, P., et al. (2010). Candidaemia associated with decreased in vitro fluconazo,le susceptibility: is Candida speciation predictive of the susceptibility pattern?. Journal of Antimicrobial Chemotherapy, 65:1460-1465.

Raekiansyah, M., Buerano, C.C., Luz, M.A.D., Morita, K. (2018). Inhibitory effect of the green tea molecule EGCG against dengue virus infection. Archives of Virology, 163:1649-1655.

Rahmasari, R., Haruyama, T., Charyasriwong, S., Nishida, T., Kobayashi, N. (2017). Antiviral activity 
of aspalathus linearis against human influenza virus. Natural Product Communications, 12:599-602.

Raut, J.S., Chauhan, N.M., Shinde, R.B., Karuppayil, S.M. (2013). Inhibition of planktonic and biofilm growth of Candida albicans reveals novel antifungal activity of caffeine. Journal of Medicinal Plants Research, 7(13):777-782.

Romulo, A., Zuhud, E.A.M., Rondevaldova, J., Kokoska, L. (2018). Screening of in vitro antimicrobial activity of plants used in traditional Indonesian medicine. Pharmaceutical Biology, 56:287-293

Sandai, D., Tabana, Y.M., El Quweini, A., Ayodeji, I.O. (2016). Resistance of Candida albicans biofilm to drugs and the host immune system. Jundishapur Journal of Microbiology, 9:37385.

Shahzad, M., Sherry, L., Rajendran, R., Edwards, C.A., Combet, E., Ramage, G. (2014). Utilising polyphenols for the clinical management of Candida albicans biofilms. International Journal of Antimicrobial Agents, 44:269-273.

Sorgo, A.G., Heilmann, C.J., Dekker, H.L., Bekker, M., Brul, S., de Koster, C.G., et al. (2011). Effects of fluconazole on the secretome, the wall proteome, and wall integrity of the clinical fungus Candida albicans. Eukaryotic cells, 10:1071-1081.
Tezuka, Y., Stampoulis, P., Banskota, A.H., Awale, S., Tran, K.Q., Saiki, I., et al. (2000). Constituents of the vietnamese medicinal plant Orthosiphon stamineus. Chemical and Pharmaceutical Bulletin, 48:1711-1719.

Traba, C., \& Jun F. Liang, J.F. (2011). Susceptibility of Staphylococcus aureus biofilms to reactive discharge gases. Biofouling, 27(7): 763-772.

Watanabe, K., Rahmasari, R., Matsunaga, A., Haruyama, T., Kobayashi, N. (2014). Anti-influenza viral effects of honey in vitro: potent high activity of Manuka honey. Archives of Medical Research, 45:359-365.

Zore, G.B., Thakre, A.D., Jadhav, S., Karuppayil, S.M. (2011). Terpenoids inhibit Candida albicans growth by affecting membrane integrity and arrest of cell cycle. Phytomedicine, 18:1180-1190. 